\title{
Vitamin D Deficiency in Children and Adolescents
}

\author{
Nesibe Andıran1, Nurullah Çelik1, Halise Akça2, Güzide Doğan2 \\ ${ }^{1}$ Fatih University Faculty of Medicine, Department of Pediatric Endocrinology, Ankara, Turkey \\ ${ }^{2}$ Fatih University Faculty of Medicine, Department of Pediatrics, Ankara, Turkey
}

\begin{abstract}
Objective: Vitamin D deficiency is an important health problem in both developed and developing countries. Recent reports on the extraskeletal effects of vitamin $D$ have led to increased interest in prevalence studies on states of deficiency/insufficiency of vitamin D. The aim of this study was to determine the frequency of vitamin $\mathrm{D}$ deficiency and insufficiency in children and adolescents residing in Ankara, Turkey and to investigate the factors associated with low vitamin $\mathrm{D}$ status.

Methods: A total of 440 children and adolescents aged between 0 and 16 years were enrolled in this study. The subjects were divided into three groups according to their vitamin D status (deficiency $\leq 15 \mathrm{ng} / \mathrm{mL}$; insufficiency: $15-20$ $\mathrm{ng} / \mathrm{mL}$; sufficiency $\geq 20 \mathrm{ng} / \mathrm{mL}$ ) and also according to their age (preschool $<5$ years; middle childhood: 5-10 years; adolescence: $11-16$ years).

Results: Overall, $40 \%$ of the subjects were found to have 25 hydroxy vitamin D [25(OH)D] levels of less than $20 \mathrm{ng} / \mathrm{mL}$. The levels indicated a deficiency state in 110 subjects $(25 \%)$ and insufficiency - in $66(15 \%)$. The rate of vitamin $\mathrm{D}$ deficiency was higher in girls, regardless of age. $25(\mathrm{OH}) \mathrm{D}$ levels correlated negatively with age $(r=-0.48, p<0.001)$, body mass index (BMI) ( $r=-0.20, p=0.001)$ and intact parathyroid hormone (iPTH) level $(r=-0.31, p=0.001)$. A positive correlation was observed between $25(\mathrm{OH}) \mathrm{D}$ and serum ferritin levels $(r=0.15, p=0.004)$.

Conclusions: The high frequency of vitamin $D$ deficiency in childhood (especially among adolescent girls) indicates a need for supplementation and nutritional support.

Key words: Vitamin D, deficiency, frequency, ferritin, risk factors
\end{abstract}

Conflict of interest: None declared

Received: 22.12.2011

\section{Introduction}

Vitamin D deficiency is an important public health problem in both developed and developing countries, with a reported worldwide prevalence of $30-80 \%$ in children and adults $(1,2,3)$. The role of vitamin $\mathrm{D}$ in bone mineralization is well-documented. However, only recently, numerous studies have reported a link between vitamin $\mathrm{D}$ deficiency and several chronic disorders such as type 1 diabetes mellitus (T1DM), systemic lupus erythematosus (SLE), multiple sclerosis (MS), cardiovascular disease (CVD) and several malignancies $(4,5,6,7,8)$. These recent findings have led to greater emphasis on treatment of vitamin $D$ deficiency and/or vitamin D supplementation.

Prevalence studies on vitamin D deficiency and/or insufficiency in the Turkish population, especially among prepubertal children over 3 years of age, are relatively scarce (9). The aim of this study was to determine the frequency of deficiency and insufficiency of vitamin D in a sample of Turkish children and adolescents and to investigate the factors associated with low vitamin D status.

\section{Methods}

This study was undertaken by the Fatih University Pediatrics Department and conducted in the University hospital, situated in Ankara, Turkey. We retrospectively reviewed the records of a total of 440 children and adolescents aged between 0 and 16 years who had presented to the outpatient clinic between January 2008 and January 2010. All patients were subjected to a careful physical examination. Weights were measured using a calibrated digital scale. Height measurements were done in

\section{Address for Correspondence}

Halise Akça MD, Fatih University Faculty of Medicine, Department of Pediatrics, Ankara, Turkey GSM: +90 5065871482 E-mail: haliseakca@gmail.com

(c) Journal of Clinical Research in Pediatric Endocrinology, Published by Galenos Publishing. 
triplicate to the nearest millimeter using a calibrated stadiometer. Body mass index (BMI) were calculated according to the formula [weight $(\mathrm{kg}) /$ height $(\mathrm{m})^{2}$ ]. Obesity was defined as the presence of a BMl above the 95th percentile for age and sex based on established percentile curves for Turkish children (10). Patients with a history of a chronic disorder or on any medication that may alter vitamin $D$ metabolism were excluded from the study.

Venous blood samples were obtained for all patients from the antecubital region between 8.00-8.30 am after an 8-12-hour overnight fast. Serum calcium (Ca), phosphorus $(\mathrm{P})$, magnesium $(\mathrm{Mg})$, alkaline phosphatase (ALP) and glucose levels were measured using the enzymatic colorimetric method (Roche Integra 800), while serum 25 hydroxy vitamin D [25(OH)D] levels were measured by highperformance liquid chromatography (Shimadzu UFLC). Serum levels of ferritin, insulin and intact parathyroid hormone (iPTH) were evaluated using the electrochemiluminescence method (Advia Centaur XP). Insulin resistance for each patient was estimated by the homeostatic model assessment method insulin ratio (HOMA-IR) using the formula [HOMA-IR=(glucose $X$ insulin)/405]. Vitamin D levels were estimated immediately after taking the blood sample. The same assays were used throughout the study.

For evaluation of the results, the subjects were divided into three groups according to their vitamin $D$ status (deficiency $\leq 15 \mathrm{ng} / \mathrm{mL}$; insufficiency: $15-20 \mathrm{ng} / \mathrm{mL}$; sufficiency $\geq 20 \mathrm{ng} / \mathrm{mL}$ ) (11) and also according to their age (preschool <5 years; middle childhood: 5-10 years; adolescence: 11-16 years).

\section{Statistical Analysis}

Statistical analysis was performed using SPSS 13.0 for Windows (SPSS, Inc., Chicago, IL, USA). One-way ANOVA was used in comparing variables with normal distribution. Pearson's chi-square and Fisher's exact tests were used for comparisons of categorical variables. Correlations between two variables were evaluated by Pearson's correlation coefficient. Values for all parameters, except gender, were expressed as mean \pm standard deviation, and a p-value of less than 0.05 was considered indicative of statistical significance.

\section{Results}

We retrospectively reviewed the records of a total of 440 children and adolescents aged between 0 and 16 years of age. Overall, $40 \%$ of patients had $25(\mathrm{OH}) \mathrm{D}$ levels lower than $20 \mathrm{ng} / \mathrm{mL}$ with 110 patients (25\%) having deficiency and 66 patients $(15 \%)$ having insufficiency. Comparisons between age groups in terms of vitamin $D$ levels revealed that infants had a higher mean level of $25(\mathrm{OH}) \mathrm{D}$ compared to older children, with fewer of them having insufficiency $10-5$ age group, $34.2 \pm 16.2 \mathrm{ng} / \mathrm{mL} ; 5-10$ age group, $20.5 \pm 8.7$ $\mathrm{ng} / \mathrm{mL} ; 10-16$ age group, $18.7 \pm 11.5 \mathrm{ng} / \mathrm{mL}$; Figure 1). Comparisons between age groups in terms of iPTH levels are shown in Figure 2.

Table 1. The anthtopmetric and metabolic characteristics of the study population

\begin{tabular}{|c|c|c|c|c|}
\hline \multirow[b]{2}{*}{ Variable } & \multicolumn{3}{|c|}{ Vitamin D status } & \multirow[b]{2}{*}{$\mathrm{p}$-value } \\
\hline & Deficiency & Insufficiency & Sufficiency & \\
\hline Age, years & $8.9 \pm 4.3$ & $10.6 \pm 3.6$ & $5.6 \pm 5$ & $<0.001$ \\
\hline Female (\%) & 59.1 & 64.5 & 47 & 0.005 \\
\hline BMI (kg/m²) & $19.6 \pm 4.8$ & $21.3 \pm 6$ & $18.9 \pm 5.1$ & 0.001 \\
\hline $25(0 H) D(n g / m L)(n=440)$ & $17.3 \pm 1.4$ & $10 \pm 3.1$ & $33 \pm 13.6$ & $<0.001$ \\
\hline $\mathrm{Ca}(\mathrm{mg} / \mathrm{dL})$ & $9.8 \pm 0.5$ & $9.6 \pm 0.4$ & $10.1 \pm 0.5$ & $<0.001$ \\
\hline$P(m g / d L)$ & $4.9 \pm 0.6$ & $4.6 \pm 0.6$ & $5.2 \pm 0.6$ & $<0.001$ \\
\hline $\mathrm{Mg}(\mathrm{mg} / \mathrm{dL})$ & $2.2 \pm 0.2$ & $2.06 \pm 0.8$ & $2.2 \pm 0.2$ & $<0.001$ \\
\hline $\operatorname{ALP}(U / L)$ & $234 \pm 99$ & $224.3 \pm 100$ & $238 \pm 80$ & 0.43 \\
\hline iPTH (pg/mL) (n=132) & $40.2 \pm 33$ & $48.3 \pm 32.9$ & $36.3 \pm 13.4$ & 0.002 \\
\hline Ferritin $(\mathrm{ng} / \mathrm{mL})(\mathrm{n}=358)$ & $32.4 \pm 20.9$ & $28.6 \pm 21$ & $33.8 \pm 21.5$ & 0.169 \\
\hline HOMA-IR (n=72) & $3.2 \pm 1.8$ & $3.7 \pm 2.3$ & $3.4 \pm 2.6$ & 0.81 \\
\hline
\end{tabular}


While $64.8 \%$ of adolescent girls had serum vitamin D levels below $20 \mathrm{ng} / \mathrm{mL}$, this finding was observed in only $52.1 \%$ of adolescent boys. The rate of vitamin $\mathrm{D}$ deficiency was higher in girls, regardless of age group. The anthropometric and metabolic characteristics of the study population are given in Table 1.

Children with vitamin $D$ deficiency were significantly older than those with normal serum $25(\mathrm{OH}) \mathrm{D}$ levels $(10.3 \pm 3.6$ years vs. $5.6 \pm 5$ years; $p=0.001)$. On the other hand, children with vitamin $D$ deficiency had significantly higher BMI

Table 2. Pearson's correlation coefficients of serum $25(\mathrm{OH}) \mathrm{D}$ levels with age, BMI, iPTH and ferritin levels, and HOMA-IR values

\begin{tabular}{lcc}
\hline & \multicolumn{2}{c}{$\mathbf{2 5 ( 0 H ) D}$ level $(\mathbf{n g} / \mathrm{mL})$} \\
\hline Age (year) & $\mathbf{~ r ~}$ & p \\
BMI $\left(\mathrm{kg} / \mathrm{m}^{2)}\right.$ & -0.48 & $<0.001$ \\
iPTH $(\mathrm{pg} / \mathrm{mL})$ & -0.2 & $<0.001$ \\
Ferritin $(\mathrm{ng} / \mathrm{mL})$ & -0.31 & $<0.001$ \\
HOMA-IR & 0.15 & 0.004 \\
\hline
\end{tabular}

BMI: body mass index, IPTH: intact parathyroid hormone, HOMA-IR: homeostatic model assessment method insulin ratio, 25(OH)D: 25 hydroxy vitamin D

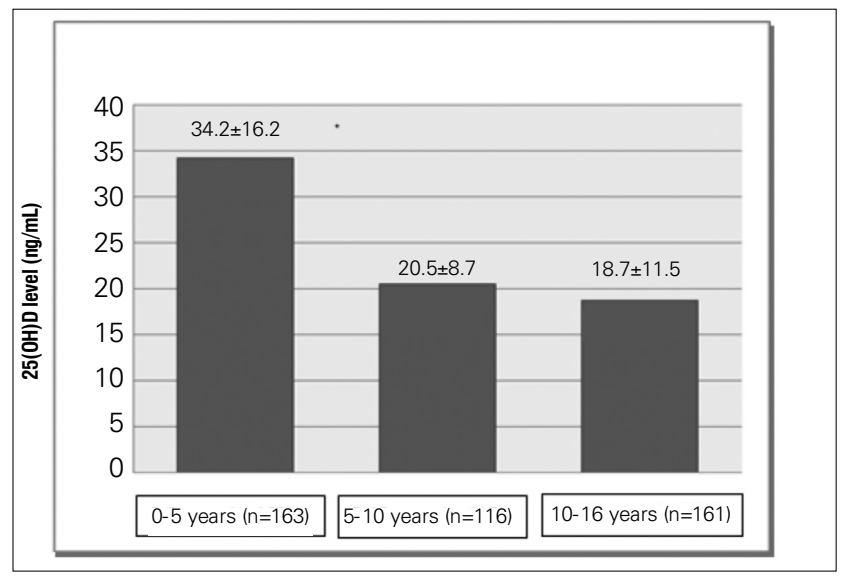

Figure 1. 25(OH)D levels in the three age groups

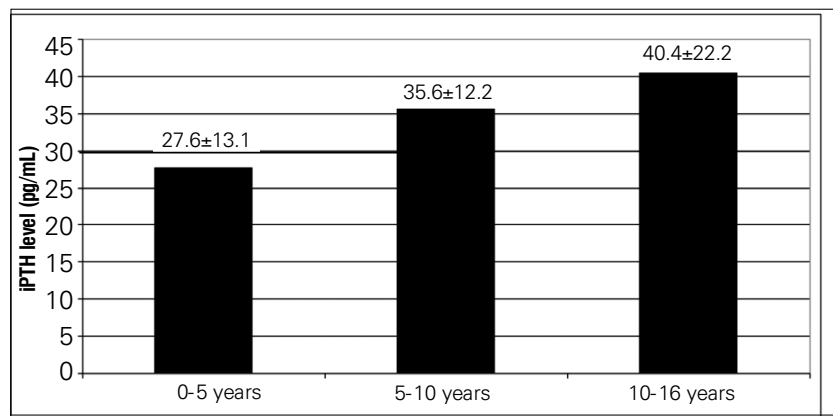

Figure 2. Intact parathyroid hormone levels in the three age groups compared to patients with higher serum levels of $25(\mathrm{OH}) \mathrm{D}$ (Table 1). Correlation analyses revealed that $25(\mathrm{OH}) \mathrm{D}$ levels correlated negatively with age $(r=-0.48, p<0.001)$, BMI $(r=-0.20, p=0.001)$, and iPTH $(r=-0.31, p=0.001)$, whereas a positive correlation was observed with serum ferritin levels $(r=0.15, p=0.004)$. No correlation was found between serum vitamin $D$ levels and HOMA-IR ( $r=-0.18, p=0.12)$. Results of correlation analyses are presented in Table 2.

Lower serum $\mathrm{Ca}$ and $\mathrm{P}$ levels, but higher levels of ALP were observed in patients with vitamin $D$ deficiency $(<15 \mathrm{ng} / \mathrm{mL})$. Significantly higher levels of iPTH were also observed in this group, indicative of the presence of a compensatory response to low 25(OH)D levels (Table 1).

\section{Discussion}

We found a remarkably high prevalence of poor vitamin D status among the 0-16 years age group included in this sample. This finding clearly indicates that vitamin D deficiency is an important health problem in children living in Ankara. However, one weak point of our study was that the prevalence was not determined on a population basis. We believe that a nationwide study would give more accurate results on the true prevalence.

Vitamin D deficiency was found to be higher in girls than in boys, especially in the adolescent age group. It was also noted that the frequency of vitamin $D$ deficiency increased with age.

Studies on adults and children have shown that vitamin D insufficiency is more prevalent among overweight and obese people $(12,13,14,15)$. Similarly, vitamin D deficiency was found to be more frequent in the obese subjects of our study. The etiopathogenesis of vitamin D deficiency in obese people is not clear. The sequestration of vitamin $D$ in the subcutaneous body fat and its consequent reduced bioavailability was suggested to explain this relationship (16). Fewer outdoor activities and reduced sunlight exposure in obese individuals have also been suggested to contribute to reduced endogenous vitamin $D$ production (17). In adults, low vitamin D status has been shown to contribute to development of cardiovascular diseases (18). A recent comprehensive study has shown that excess body weight at 14-19 years may increase cause-specific mortality in middle age (19). Therefore, the low vitamin D status observed in adolescents with excess body weight may be a contributing factor to this cause-specific mortality effect (15).

We observed lower deficiency rates in the younger age group in our sample. This finding is probably related to preventive measures in primary health care conducted by the Ministry of Health in Turkey. Since 2005, vitamin D supplements are distributed to every newborn throughout their infancy at no 
financial cost (20). Furthermore, families and physicians tend to use multivitamins more frequently in younger age groups. In a study conducted in Israel, frequency of vitamin $D$ deficiency was also found to be lower in the age group between 0 and 5 years compared to other age groups (3). Similar findings have also been recently reported by large demographic analyses conducted in the U.S. (21).

It has been reported that vitamin $D$ insufficiency is more prevalent among girls $(3,21)$. In a group of Turkish girls aged 14-18 years, prevalence of vitamin $D$ insufficiency was reported to vary between $15.6 \%$ and $59.4 \%$, according to socio-economic status and season (22). In our sample, considering all age groups, we found vitamin D deficiency to be higher in the girls. Unlike the study by Oren et al (3), vitamin $D$ deficiency in girls was recorded also in the older age groups in our study. Vitamin D levels were below 20 $\mathrm{ng} / \mathrm{mL}$ in $64.8 \%$ of adolescent girls between 10 and 16 years of age. This may be due to the clothing habits in Turkish girls and/or less time spent on outdoor activities (23). Recent studies suggest that vitamin $D$ deficiency is particularly common among young women who wear concealing clothing $(23,24)$ and that these young women are also at increased risk for osteoporosis $(25,26)$.

The limited number of studies conducted on this issue have shown a positive correlation between the levels of $25(\mathrm{OH}) \mathrm{D}$ and ferritin. Constantini et al (27) reported a positive correlation between the levels of $25(\mathrm{OH}) \mathrm{D}$ and ferritin in athletes and dancers. Similarly, a positive correlation was reported between these two parameters in patients with Crohn's disease (28). In our study also, ferritin level was likely to be lower in individuals with low $25(\mathrm{OH}) \mathrm{D}$ levels. This relationship may be explained by suboptimal dietary habits (27). This link is further supported by studies showing that $1 \alpha, 25$-dihydroxycholecalciferol, an active form of vitamin $D$, leads to an increase in intestinal Fe absorption by elevating the erythropoietin level (29). The abovementioned studies indicate that periodic screening should be performed for both vitamin D deficiency and low ferritin levels, two insidious conditions of high prevalence.

In conclusion, vitamin D deficiency and insufficiency were found to be highly prevalent in our study group of children aged $0-16$ years. This finding is in line with the high rate of vitamin D insufficiency recorded in Turkish infants and children, especially in girls and adolescents reported recently. The insufficiency state may be caused by low sunshine exposure, skin pigmentation, air pollution, skin covering and low vitamin $D$ intake. According to our study, vitamin D supplementation should be provided not only for infants, but also for children of all ages, including adolescents.

\section{Conclusion}

We concluded that vitamin $D$ deficiency and insufficiency are highly prevalent in children aged 0 to 16 . In our country, a high rate of vitamin D insufficiency is recorded in all age groups of children, especially in girls and adolescents. It may be caused by low sunshine exposure, skin pigmentation, air pollution, skin covering and low vitamin D intake. According to our study, it seems that vitamin D supplement should be provided not only for infants, but also for all the children, especially for those of in adolescent period.

\section{References}

1. Calvo MS, Whiting SJ, Barton CN. Vitamin D intake: a global perspective of current status. J Nutr 2005;135:310-316.

2. Holick MF. Vitamin D deficiency. N Engl J Med 2007;357:266281.

3. Oren Y, Shapira Y, Agmon-Levin N, Kivity S, Zafrir Y, Altman A, Lerner $A$, Shoenfeld $Y$. Vitamin D insufficiency in a sunny environment: a demographic and seasonal analysis. Isr Med Assoc J 2010;12:751-756.

4. Hypponen E, Laara E, Reunanen A, Jarvelin MR, Virtanen SM. Intake of vitamin $\mathrm{D}$ and risk of type 1 diabetes: a birth-cohort study. Lancet 2001;358:1500-1503.

5. Amital H, Szekanecz Z, Szücs G, Dankó K, Nagy E, Csépány T, Kiss E, Rovensky J, Tuchynova A, Kozakova D, Doria A, Corocher N, Agmon-Levin N, Barak V, Orbach H, ZandmanGoddard G, Shoenfeld Y. Serum concentrations of $25-\mathrm{OH}$ vitamin $D$ in patients with systemic lupus erythematosus (SLE) are inversely related to disease activity: is it time to routinely supplement patients with SLE with vitamin D? Ann Rheum Dis 2010;69:1155-1157.

6. Ascherio A, Munger KL, Simon KC. Vitamin D and multiple sclerosis. Lancet Neurol 2010;9:599-612.

7. Trump DL, Deeb KK, Johnson CS. Vitamin D: considerations in the continued development as an agent for cancer prevention and therapy. Cancer J 2010;16:1-9.

8. Martins D, Wolf M, Pan D, Zadshir A, Tareen N, Thadhani R, Felsenfeld A, Levine B, Mehrotra R, Norris K. Prevalence of cardiovascular risk factors and the serum levels of 25hydroxyvitamin D in the United States: data from the Third National Health and Nutrition Examination Survey. Arch Intern Med 2007;167:1159-1165.

9. Akman AO, Tumer L, Hasanoglu A, Ihan M, Cayci B. Frequency of vitamin $D$ insufficiency in healthy children between 1 and 16 years of age in Turkey. Pediatr Int 2011;53:968-973.

10. Bundak R, Furman A, Gunoz H, Darendeliler F, Bas F, Neyzi O. Body mass index references for Turkish children. Acta Paediatr 2006;95:194-198.

11. Misra M, Pacaud D, Petryk A, Collett-Solberg PF, Kappy M; Drug and Therapeutics Committee of the Lawson Wilkins Pediatric Endocrine Society. Vitamin D deficiency in children and its management: review of current knowledge and recommendations. Pediatrics 2008;122:398-417. 
12. Rajakumar K, de Las HJ, Chen TC, Lee S, Holick MF, Arslanian SA. Vitamin D Status, Adiposity, and Lipids in Black American and Caucasian Children. J Clin Endocrinol Metab 2011:96:1560-1567.

13. Alemzadeh R, Kichler J, Babar G, Calhoun M. Hypovitaminosis $D$ in obese children and adolescents: relationship with adiposity, insulin sensitivity, ethnicity, and season. Metabolism 2008;57:183-191.

14. Reis JP, von MD, Miller ER, III, Michos ED, Appel LJ. Vitamin D status and cardiometabolic risk factors in the United States adolescent population. Pediatrics 2009;124:371-379.

15. Lagunova Z, Porojnicu AC, Lindberg FA, Aksnes L, Moan J. Vitamin D status in Norwegian children and adolescents with excess body weight. Pediatr Diabetes 2011;12:120-126.

16. Wortsman J, Matsuoka LY, Chen TC, Lu Z, Holick MF. Decreased bioavailability of vitamin D in obesity. Am J Clin Nutr 2000;72:690-693.

17. Rajakumar K, Fernstrom JD, Holick MF, Janosky JE, Greenspan SL. Vitamin D status and response to Vitamin D(3) in obese vs. non-obese African American children. Obesity (Silver Spring) 2008;16:90-95.

18. Cheng S, Massaro JM, Fox CS, Larson MG, Keyes MJ, McCabe EL, Robins SJ, O'Donnell CJ, Hoffmann U, Jacques PF, Booth SL, Vasan RS, Wolf M, Wang TJ. Adiposity, cardiometabolic risk, and vitamin D status: the Framingham Heart Study. Diabetes 2010;59:242-248.

19. Bjorge T, Engeland A, Tverdal A, Smith GD. Body mass index in adolescence in relation to cause-specific mortality: a followup of 230,000 Norwegian adolescents. Am J Epidemiol 2008;168:30-37.

20. Hatun S, Bereket A, Ozkan B, Coskun T, Kose R, Calikoglu AS. Free vitamin $D$ supplementation for every infant in Turkey. Arch Dis Child 2007;92:373-374.
21. Mansbach JM, Ginde AA, Camargo CA Jr. Serum 25hydroxyvitamin $D$ levels among US children aged 1 to 11 years: do children need more vitamin D? Pediatrics 2009;124:1404-1410.

22. Olmez D, Bober E, Buyukgebiz A, Cimrin D. The frequency of vitamin $D$ insufficiency in healthy female adolescents. Acta Paediatr 2006;95:1266-1269.

23. Hatun S, Islam O, Cizmecioglu F, Kara B, Babaoglu K, Berk F, Gökalp AS. Subclinical vitamin D deficiency is increased in adolescent girls who wear concealing clothing. J Nutr 2005;135:218-222.

24. Guzel R, Kozanoglu E, Guler-Uysal F, Soyupak S, Sarpel T. Vitamin $D$ status and bone mineral density of veiled and unveiled Turkish women. J Womens Health Gend Based Med 2001;10:765-770.

25. Allali F, El aS, Saoud B, Maaroufi H, Abouqal R, HajjajHassouni $\mathrm{N}$. The impact of clothing style on bone mineral density among post menopausal women in Morocco: a casecontrol study. BMC Public Health 2006;6:135.

26. Andiran N, Yordam N, Ozön A. Risk factors for vitamin D deficiency in breast-fed newborns and their mothers. Nutrition 2002;18:47-50.

27. Constantini NW, Arieli R, Chodick G, Dubnov-Raz G. High prevalence of vitamin $\mathrm{D}$ insufficiency in athletes and dancers. Clin J Sport Med 2010;20:368-371.

28. Tajika M, Matsuura A, Nakamura T, Suzuki T, Sawaki A, Kato T, Hara K, Ookubo K, Yamao K, Kato M, Muto Y. Risk factors for vitamin $D$ deficiency in patients with Crohn's disease. J Gastroenterol 2004;39:527-533.

29. Dusso AS, Puche RC. The effect of 1 alpha, 25dihydroxycholecalciferol on iron metabolism. Blut 1985;51:103-108. 